\title{
SOJA: AVALIAÇÃO DE LINHAGENS COM PERIODO JUVENIL LONGO E OBTENÇÃO DO CULTIVAR IAC-15
}

\author{
MANOEL ALBINO COELHO DE MIRANDA (2,\%), \\ HIPÓLITO ASSUNÇĀO ANTONIO MASCARENHAS (2,\%), \\ JOSÉ CARLOS VLA NOVA ALVES PEREIRA (3), PAULO BOLLER GALLO (4), \\ SÉRGIO ROCHA LIMA DIEHL (9) • NORMA RAHAL PINZAN (9)
}

\section{RESUMO}

Buscando desenvolver cultivares de soja de maior capacidade produtiva e melhor adaptaçăo as condiçoses paulistas, realizaram-se hibridaç̋es ente material genético com perfodo juvenil longo, as quais possibilitaram a obtençåo de linhagens que, por sua vez, foram avaliadas em ensaios preliminares e regionais, no ambito do Instituto Agronomico. Concomitantemente, para que o sojicultor tivesse à sua disposiçăo os cultivares mais produtivos, independentemente da procedencia, realizaram-se testes regionais de avaliaçăo pelo Sistema de Avaliaçăo e Recomendaçăo de Cultivares de Soja para o Estado de Săo Paulo - trabalho de cooperaçăo entre o Instituto Agronómico (IAC) e a Coordenadoria de Assistencia Técnica Integral (CATI) - nas regiöes produtbras, com técnica e recursos ali disponiveis. Os ensaios preliminares foram delineados em látice simples $6 \times 6$ e os ensaios regionais e os testes em blocos ao acaso, com quatro repeticoes. Os resultados, tanto dos experimentos deservolvidos no IAC como os do Sistema de Avaliaçăo IAC-CAT, permitiram avaliar o desempenho e justificar o lançamento e recomendaçăo do cultivar IAC-15 para o Estado de Săo Paulo.

Tormos de indexaçăo: soja, seleçăo, porfodo juvonil, sdapteçåo, cultiveres.

\section{ABSTRACT}

\section{STUDY OF SOYBEAN LINES WITH LONG JUVENILE PERIOD RELEASE OF CULTIVAR IAC-15}

To develop soybean cultivars with high productive capacity and good adaptation to the climatic conditions of the State of Sao Paulo, Brazil,

\footnotetext{
(1) Recebido pare publicagão om 23 de abril e acoito em 3 de agosto de 1990.

(2) Seçäo de Lequminoses, Instituto Agronómico (IAC), Caix Postal 28, 13001 Campinas (SP).

(3) Estaçä̌ Exporimental do Ribeirăo Preto (IAC).

(4) Estaçäo Experimontal de Mococe (IAC).

(5) Depertemento de Extenszo Rural, Coordenedoria de Assisténcia T6́cnica Integral (CATI).

(9) Com bolsa de peequiea do CNPq.
} 
hybridizations were made involving soybean parental material with long juvenile period. Lines were selected and evaluated in preliminary and regional experiments carried out at the experimental stations of the Instituto Agronomico. In order to provide soybean growers with the most productive cultivars, regardless of its origin, simultaneous varietal tests were performed by the instituto Agronomico de Campinas/Coordenadoria de Assistencia Técnica Integral system in the areas where soybeans are cultivated. In the preliminary experiments a simple lattice design $(6 \times 6)$ was utilized whereas, in the regional varietal tests a randomized block design was used with four replications. The release of the soybean cultivar IAC-15 was a result of these regional experiments.

Index terme: selection, juvenile period, adeptation, cultivers.

\section{INTRODUÇÃO}

O principal objetivo do programa de melhoramento da soja, pela Seção de Leguminosas do Instituto Agronómico, 6 aumentar a produtividade, para que 0 sojicultor possa auterir maiores lucros, sem a necessidade de investimentos adicionais, quanto aos outros fatores de produçăo. Ao mesmo tempo, busca-se aumentar a capacidade adaptativa dos cultivares em relação ao clima $\theta$ ao solo, a resistencia a doenças e pragas $\theta$, mais recentemente, melhorar a qualidade do óleo e da proteina dos gräos.

No que se refere a produtividade, conseguiu-se, no Estado de São Paulo, uma consistent elevaçăo, de 744kg/ha, em 1945 (Relatorio da Comissåo Técnica de Soja, citado por MASCARENHAS ot al., 1983) a $2.278 \mathrm{~kg} / \mathrm{ha}$, em 1989 (PROGNÓSTICO AGRICOLA, 1988/89), o que corresponde a um acréscimo de $34,9 \mathrm{~kg} / \mathrm{ha} / \mathrm{ano}$. Esse aumento se deve tento ao desenvolvimento de novos cultivares como à melhoria das condições de solo (correção $\theta$ adubação) $\theta$ toda uma tocnologia de produção adequada. SPECHT \& WILLIAMS (1984) relatam um incremento de $18,8 \mathrm{~kg} / \mathrm{ha} / \mathrm{ano}$, decorrente do melhoramento genético, nos EUA, o que reforça a importancia da criaçāo de cultivares de maior capacidade produtiva.

Em relação ao aumento da capacidade adaptativa, a incorporação de fatores para perlodo juvenil longo, nos cultivares IAC, permite a antecipaçāo do plantio de novembro para setembro-outubro, e o cultivo de outono-inverno com soja irrigada, em áreas livres de geada. Entende-se por perfodo juvenil, em soja, que é planta de dias curtos, um estádio de desenvolvimento no qual, mesmo existindo noites com número de horas de escuro necessário para a induçăo ao florescimento de determinado cultivar, este deixa de responder ao estrmulo reprodutivo (NOGUEIRA, 1983).

As semeaduras antecipadas, setembro-outubro, induzem ciclos plantio-maturação maiores devido a interação entre periodo juvenil e resposta ao fotoperíodo, condicionando um acréscimo no número de internódios e, conseqüentemente, maiores acumulaçōes terrmicas, redundando em maior produtividade (CAMARGO et al., 1988). 
Visando ao aumento da produtividade e da adaptação, criou-se o cultivar IAC-15. Este trabalho tem por finalidade demonstrar o método e os resultados que permitiram seu desenvolvimento $e$ avaliação.

\section{MATERIAL E MÉTODOS}

Cultivares mais produtivos, que apresentavam atributos desejados, foram cruzados, procurando-se reunir na descendencia os méritos dos pais.

No quadro 1 tem-se a genealogia dos cultivares $\theta$ linhagens desenvolvidas no IAC e que constituíram o material tasto nos diferentes ensaios. Pode-se constatar a preocupação em obter cultivares de período juvenil longo, mesmo em genóipos precoces, pela utilizaçäo intensiva, nas hibridaçōes do cultivar Parana: este é proveniente de uma linhagem da Carolina do Norte, EUA, N59-6800, do cruzamento [Hill X F 1 (Roanoke X Ogden)], do grupo V, da escala de maturação norte-americana, portanto, de latitude muito acima daquela correspondente à do Estado de Sāo Paulo, que está em torno de $21^{\circ} \mathrm{S}$. Assim, caso năo possuísse período juvenil longo, quando plantado nas nossas condiçōes, encontraria noites indutivas e floresceria precocemente, não atingindo altura suficiente para colheita mecanica.

Como este cultivar vem apresentando altura adequada para a colheita mecanica $(60 \mathrm{~cm})$, conclui-se que possui perfodo juvenil; mesmo sendo de ciclo precoce e de crescimento determinado. Reforçando essa afirmativa, PEDRO JR. et al. (1984) apontaram que esse genotipo independentemente da época de semeadura, entre outubro e dezembro, mostrava sempre o mesmo número de internódios, ficando, pois, diminuta a importancia do fotoperiodo, na previsão da sua produtividade.

No "pedigree" do 'IAC-15' (IAC 82-1174), além dessa forte de perlodo juvenil longo, encontra-se a originada de 'Davis', detectada por TISSELLI F. (1981) e a do cruzamento de Hill X PI 240.664, que provavelmente alongaram ainda mais o periodo juvenil do cultivar IAC-15, pois a linhagem IAC77-3086 6 cruzamento de Paraná XF, (Davis X IAC73-1364), sendo esta última proveniente de Davis X IAC71-1113 e a IAC71-1113 da hibridação entre PI 240.664 X Hill. De linhagens deste último cruzamento hibridadas com cultivares norte-americanos originaram os principais cultivares utilizados em baixas latitudes, como IAC-8, Doko e Tropical, portanto com perfodo juvenil longo (MIRANDA et al., 1980; KIIHL et al., 1982, o ALMEIDA ot al., 1982).

Esta menor sensibilidade ao efeito de latitude pode ter sido herdada do cultivar Hill, já apontada por KIIHL (1968) e HARTWG \& KIIHL (1979) como tendo um comportamento diferencial em relaçăo a tal parametro, quando comparado com outros genotipos de grupos de maturaçăo mais tardios.

Em outra linha de atuaçāo, buscava-se a resistencia a insetos mastigadores, com os cruzamentos que inclufam a linhagem D72-9601-1, com resistencia às lagartas Anticarsia gemmatalis e Pseudoplusia includens (REZENDE et al., 1980), e a IAC73-5115 (IAC-8), que apresenta perlodo juvenil longo e resistencia aos nematoides de galhas. 
QUADRO 1. Genealogia das linhagens e cultivares de soja avaliados nos ensaios preliminares em Campinas, Ribeirăo Preto, Gualra e Assis, em 1983/84

\begin{tabular}{|c|c|}
\hline $\begin{array}{c}\text { Cultivares } \\
e \\
\text { Linhagens }\end{array}$ & Genealogia \\
\hline $\begin{array}{l}\text { IAC-10 ... } \\
\text { IAC-12 ... } \\
\text { IAC82-303 } \\
\text { IAC82-339 } \\
\text { IAC82-616 } \\
\text { IAC82-623 } \\
\text { IAC82-648 } \\
\text { IAC82-656 } \\
\text { IAC82-698 } \\
\text { IAC82-907 } \\
\text { IAC82-1093 } \\
\text { IAC82-1112 } \\
\text { IAC82-1173 } \\
\text { IAC82-1174 } \\
\text { IAC82-1238 } \\
\text { IAC82-1291 } \\
\text { IAC82-3117 } \\
\text { IAC82-3127 } \\
\text { IAC82-3128 } \\
\text { IAC82-3135 } \\
\text { IAC82-3138 } \\
\text { IAC82-3168 } \\
\text { IAC82-3181 } \\
\text { IAC82-3185 } \\
\text { IAC82-3193 } \\
\text { IAC82-3204 } \\
\text { IAC82-3207 } \\
\text { IAC82-3209 } \\
\text { IAC82-3213 } \\
\text { IAC82-3223 } \\
\text { IAC82-3308 } \\
\text { IAC82-3370 } \\
\text { IAC82-3372 } \\
\text { IAC82-3381 } \\
\text { IAC82-3405 } \\
\text { IAC82-3413 } \\
\text { IAC79-440 } \\
\text { IAC79-986 } \\
\text { IAC80-1146 }\end{array}$ & 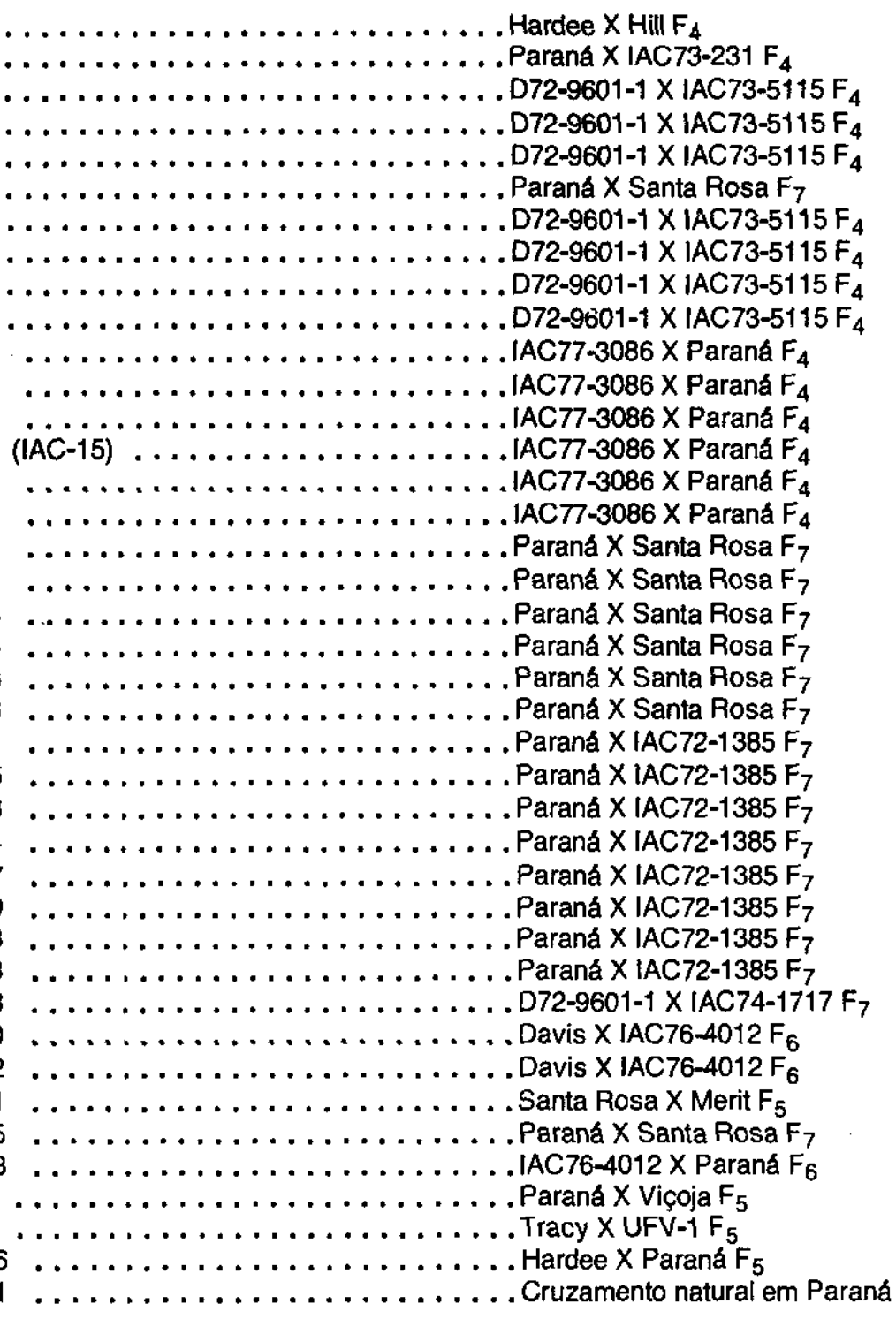 \\
\hline
\end{tabular}


Ainda merece destaque a introduçăo de fatores que diminulam a permeabilidade do tegumento dos gräos, para melhorar a qualidade fisiologica das sementes, existentes na linhagem IAC76-4012 (TAVARES et al., 1986, 1987), assim como aqueles responsáveis pelo nāo-manchamento das sementes causado pelo mosaico comum da soja, mancha-café, existente no cultivar Davis (LIMA NETO \& COSTA, 1975, \& KIIHL, 1976), incorporados em algumas linhagens testadas.

Para viabilizar as hibridaçōes pela coincidencia de florescimento entre cultivares de ciclos diferentes, os genótipos foram semeados em casa de vegetação, em sete épocas, a partir de dezembro, com intervalos de sete dias. A técnica utilizada na emasculação e polinização foi a mesma descrita por SEDIYAMA etal. (1982).

As sementes dos cruzamentos, realizados em janeiro e fevereiro, foram postas a germinar em casa de vegetação durante o inverno, utilizando-se luzes incandescentes e fluorescentes para evitar o florescimento precoce e aumentar o período luminoso, visando obter máxima produção de sementes na geração $F_{1}$. Em outubro, as sementes $F_{2}$ foram levadas ao campo, em Campinas, onde se fez seleção para caracteres de herança simples ou de alta herdabilidade. A seleção no plantio de outubro, para porte de planta, quando as noites sảo indutivas, permite discriminar o material com perfodo juvenil pela altura de planta. Os genes para período juvenil são de alta herdabilidade e recessivos, o que facilita a seleção (KIIHL, 1976, ө TISSELLI F. ${ }^{\circ}$ 1981). Após essa primeira seleçăo, seguiu-se o método genealógico até a geração $F_{4}, F_{5}, F_{6} \in F_{7}$, dependendo do cruzamento $\theta$. da uniformidade das linhagens.

A primeira avaliação para produtividade, visando reduzir o número de genótipos, fez parte dos ensaios preliminares realizados em Campinas, Ribeirão Preto, Guaíra e Assis, com delineamento em látice simples $(6 \times 6)$, sendo as parcelas constituídas de tês linhas de $4 \mathrm{~m}$ de comprimento, espaçadas de $0,60 \mathrm{~m}$. Para efeito de colheita, somente a linha central foi utilizada, eliminando-se $0,50 \mathrm{~m}$ de cada extremidade. No quadro 1 estäo relacionados os 36 tratamentos, a saber: dois padrões, IAC-10 e IAC-12, e as 34 linhagens da série 1982.

Numa terceira fase, para avaliação em diversos ambientes, os genótipos foram testados em ensaios regionais, nas Estaçöes Experimentais do IAC, durante dois anos consecutivos. Mais recentemente, foi introduzida, com o auxflio da Coordenadoria de Assistencia Técnica Integral (CATI), uma quarta etapa, na qual os ensaios são conduzidos no nivel de agricultor, com.a técnica e recursos af disponiveis, para espelhar da maneira mais realista possivel as condições da sojicultura paulista.

Os ensaios e testes regionais foram instalados nas regiőes produtoras, com delineamento em blocos ao acaso, com quatro repetições por local. As parcelas foram constituídas de quatro linhas de $6 \mathrm{~m}$ para os ensaios regionais e $5 \mathrm{~m}$ para os testes regionais, colhendo-se as duas linhas centrais $\theta$ retirando-se $0,50 \mathrm{~m}$ de cada extremidade. O espaçamento foi o utilizado pelo agricultor, de 0,45 a $0,60 \mathrm{~m}$ entre linhas. Realizou-se a análise da variância por local e, a seguir, a análise conjunta. Para comparação da média dos tratamentos, em relação ao padrāo Bossier, utilizou-se a diferença minima significativa (STEEL \& TORRIE, 1960). 
No ensaio regional de genótipos com ciclo semiprecoce, em 1984/85, foram testados os cultivares Bossier, o mais plantado, o o lAC-12, padrão de maior produtividade, juntamente com as linhagens selecionadas nos ensaios preliminares. Os ensaios foram instalados em Campinas, Gualra E.R. (Escritrio Regional do $\mid A C)$, Gualra F.R. (Fazenda Rodeio), Ituverava e Orlandia (Quadro 4).

Em 1985/86, foram incluldos os cultivares FT-10 da Companhia FT Pesquisa e Sementes e as linhagens que vinham tendo bom desempenho em produtividade em ensaios anteriores, como IAC79-440, IAC79-986, IAC80-1146 IAC80-1441, e retiradas as linhagens IAC82-1291, IAC82-3127, IAC82-1112 • IAC82-1173. Os experimentos foram implantados em Campinas, Ituverava K.O. (Kiniti Okano) e Ituverava M.Y. (Mitsuo Yamaguti) e Guafra (Quadro 6).

Nos testes regionais de 1985/86 e 1986/87 foram avaliados dois genotipos do Centro Nacional de Pesquisa de Soja, EMBRAAP quato da FT-Pesquisa e Sementes e quatro do IAC, com os mesmos padröes dos ensaios regionais Bossier e IAC-12, nas localidades de Ituverava e Gualra, em 1985/86, e em Campinas, Presidentr Venceslau, Ituvverava e Ipuă em 1986/87 (Quadro 8).

Com os resultados desses ensaios, realizou-se a recomendação de cultivares para o Estado de Sảo Paulo. O material, para ser recomendado, deveria superar em 3\% o padrão mais plantado, conforme normas do șistema de avaliação.

\section{RESULTADOS E DISCUSSÃO}

Nos quadros 2 e 3, encontram-se os resultados obtidos nos ensaios proliminares, realizados em 1983/84.

Selecionaram-se as dez linhagens mais produtivas, baseando-se na média de todos os locais.

Dos oito cruzamentos que originaram linhagens participantes do ensaio preliminar de 1983/84 (Paraná X Santa Rosa e Paraná X IAC72-1385, cada um com 13,53\%, em relaçăo ao total do material avaliado; D72-9601-1 XIAC73-5115, com 20,59\%; IAC 77-3086 X Parana, com 17,56\%; Davis X IAC76-4012, com 5,88\%, e D72-9601-1 X IAC74-1717, Santa Rosa X Merit e IAC76-4012 X Paraná com 2,94\%), somente quatro forneceram material para o ensaio regional, sendo a participação do cruzamento IAC77-3086 X Paraná de 60\%, nesto experimento, vindo a seguir Paraná $X \mid A C 72-1385$, com $20 \%$, e com $10 \%$ as hibridaçoes Paraná X Santa Rosa e D72-9601-1 X IAC73-5115. Diante desses resultados, a avaliaçăo precoce para identificaçăo dos melhores cruzamentos, conforme propőe TOLEDO (1987), parece ser totalmente justificavel.

Pelo quadro 3, pode-se aquilatar a eficiencia de seleção em semeaduras de setembo-outubro, para identificação de genótipos que apresentem período juvenil longo, pois, das linhagens testadas, somente a lAC82-3308 não atingiu a altura minima desejada $(0,60 \mathrm{~m})$, na média das localidades. 
QUADRO 2. Produtividade de linhagens e cultivares de soja avaliados nos ensaios preliminares em quatro localidades, em 1983/84

\begin{tabular}{|c|c|c|c|c|c|}
\hline Tratamentos & Assis & Guaira & Campinas & Ribeirão Preto & Média \\
\hline & & & - $\mathrm{kg} / \mathrm{ha}$ & & \\
\hline IAC82-3185 & 2.367 & 2.571 & 2.396 & 4.021 & 2.839 \\
\hline IAC82-1291 & 2.563 & 2.692 & 2.680 & 3.334 & 2.818 \\
\hline IAC82-3127 & 2.305 & 3.346 & 2.284 & 3.250 & 2.797 \\
\hline IAC82-1093 & 2.117 & 3.217 & 1.992 & 3.313 & 2.660 \\
\hline IAC-12 & 2.825 & 2.667 & 2.167 & 2.959 & 2.655 \\
\hline IAC82-648 & 2.325 & 2.663 & 2.284 & 3.188 & 2.615 \\
\hline IAC82-1112 & 1.492 & 3.184 & 2.230 & 3.480 & 2.597 \\
\hline IAC82-3209 & 2.375 & 2.596 & 2.430 & 2.917 & 2.580 \\
\hline IAC82-1173 & 2.230 & 2.584 & 1.709 & 3.584 & 2.527 \\
\hline IAC82-1174 (IAC-15) & 2.084 & 2.600 & 2.000 & 3.375 & 2.515 \\
\hline IAC82-1238 & 1.980 & 3.009 & 1.792 & 3.271 & 2.513 \\
\hline IAC82-3138 & 2.305 & 2.205 & 2.180 & 3.334 & 2.506 \\
\hline IAC82-3128 & 2.388 & 2.584 & 1.638 & 3.250 & 2.465 \\
\hline IAC82-3223 & 1.959 & 2.696 & 2.200 & 2.855 & 2.428 \\
\hline IACB2-3168 & 1.875 & 2.129 & 2.367 & 3.125 & 2,382 \\
\hline IAC82-3213 & 2.292 & 2.459 & 2.230 & 2.500 & 2.371 \\
\hline IAC82-3381 & 2.084 & 1.963 & 2.096 & 3.105 & 2.312 \\
\hline IAC82-3204 & 2.271 & 2.213 & 2.075 & 2.563 & 2.281 \\
\hline IAC82-3193 & 2.063 & 2.230 & 2,138 & 2.688 & 2.280 \\
\hline IAC82-3135 & 1.284 & 3.067 & 2.180 & 2.500 & 2.258 \\
\hline IAC82-3207 & 1.938 & 2.421 & 1.992 & 2,605 & 2.239 \\
\hline IAC82-3405 & 2.784 & 2.650 & 2.075 & 1.271 & 2.195 \\
\hline IAC82-3117 & 2.167 & 2.284 & 1.513 & 2.688 & 2.163 \\
\hline IAC-10 & 1.555 & 2.034 & 2.084 & 2.959 & 2.158 \\
\hline IAC82-907 & 1.930 & 2.405 & 1.750 & 2.521 & 2.152 \\
\hline IAC82-698 & 2.138 & 2.117 & 2.200 & 2.063 & 2.130 \\
\hline IAC82-3413 & 1.430 & 2.200 & 2.096 & 2.771 & 2.125 \\
\hline IAC82-656 & 1.959 & 2.075 & 1.625 & 2.813 & 2.118 \\
\hline IAC82-3372 & 1.742 & 2.259 & 1.688 & 2.563 & 2.063 \\
\hline IAC82-3308 & 1.084 & 2.825 & 1.688 & 2.625 & 2.056 \\
\hline IAC82-3181 & 1.646 & 1.967 & 2.034 & 2.542 & 2.048 \\
\hline IAC82-616 & 1.646 & 2.055 & 1.709 & 2.667 & 2.020 \\
\hline IAC82-3370 & 2.096 & 1.884 & 1.959 & 2.084 & 2.006 \\
\hline IAC82-339 & 2.021 & 2.046 & 1.584 & 2.313 & 1.991 \\
\hline IAC82-623 & 1.409 & 2.284 & 1.667 & 2.459 & 1.955 \\
\hline IAC82-303 & 1.555 & 1.875 & 1.845 & 2.000 & 1.819 \\
\hline Média & 2.009 & 2.446 & 2.017 & 2.821 & 2.324 \\
\hline C.V.\% & 20,94 & 16,37 & 14,60 & 24,40 & - \\
\hline
\end{tabular}


QUADRO 3. Altura média de plantas de linhagens e cultivares de soja obtida nos ensaios preliminares, em quatro localidades em 1983/84

\begin{tabular}{lrrrrr}
\hline Tratamentos & Assis & Gualra & Campinas & Ribeirăo Preto & Média \\
\hline & & & & & \\
& & & & & \\
IAC82-3185 & 75 & 71 & 87 & 90 & 81 \\
IAC82-1291 & 115 & 106 & 105 & 100 & 107 \\
IAC82-3127 & 63 & 80 & 91 & 85 & 80 \\
IAC82-1093 & 85 & 95 & 99 & 110 & 98 \\
IAC-12 & 75 & 75 & 98 & 85 & 84 \\
IAC82-648 & 95 & 82 & 100 & 95 & 88 \\
IAC82-1112 & 80 & 89 & 97 & 105 & 93 \\
IAC82-3209 & 70 & 100 & 98 & 100 & 92 \\
IAC82-1173 & 110 & 100 & 99 & 110 & 105 \\
IAC82-1174 (IAC-15) & 87 & 93 & 108 & 105 & 99 \\
IAC82-1238 & 113 & 99 & 105 & 120 & 110 \\
IAC82-3138 & 73 & 72 & 91 & 90 & 82 \\
IAC82-3128 & 73 & 85 & 92 & 105 & 89 \\
IAC82-3223 & 90 & 87 & 93 & 100 & 93 \\
IAC82-3168 & 87 & 78 & 92 & 95 & 88 \\
IAC82-3213 & 83 & 85 & 100 & 90 & 90 \\
IAC82-3381 & 101 & 110 & 116 & 130 & 115 \\
IAC82-3204 & 74 & 75 & 88 & 85 & 81 \\
IAC82-3193 & 78 & 79 & 97 & 105 & 90 \\
IAC82-3135 & 53 & 62 & 76 & 65 & 64 \\
IAC82-3207 & 87 & 93 & 103 & 100 & 96 \\
IAC82-3405 & 86 & 77 & 96 & 95 & 89 \\
IAC82-3117 & 70 & 74 & 97 & 95 & 84 \\
IAC-10 & 85 & 89 & 96 & 110 & 99 \\
IAC82-907 & 80 & 72 & 87 & 80 & 80 \\
IAC82-698 & 83 & 81 & 93 & 90 & 87 \\
IAC82-3413 & 57 & 80 & 92 & 100 & 83 \\
IAC82-656 & 70 & 63 & 82 & 75 & 73 \\
IAC82-3372 & 87 & 104 & 112 & 105 & 102 \\
IAC82-3308 & 36 & 52 & 45 & 50 & 46 \\
IAC82-3181 & 68 & 71 & 83 & 90 & 78 \\
IAC82-616 & 80 & 87 & 96 & 80 & 81 \\
IAC82-3370 & 93 & 104 & 105 & 100 & 101 \\
IAC82-339 & 53 & 63 & 69 & 65 & 63 \\
IAC82-623 & 75 & 80 & 100 & 95 & 88 \\
IAC82-303 & 83 & 50 & 105 & 95 & 84 \\
Média & 80 & 83 & 95 & 95 & 89 \\
\hline & & & & &
\end{tabular}


No quadro 4, encontram-se os resultados dos ensaios regionais de 1984/85. Pela análise da variância, pode-se verificar que houve significância para efeito de tratamento em quatro das cinco localidades.

Pela análise conjunta dos resultados das cinco localidades, as linhagens IAC82-3127 e IAC82-648 foram as únicas que näo diferiram estatisticamente do padrão Bossier. A produtividade média das linhagens IAC82-1238, IAC83-3209 e IAC 82-1093 e do cultivar IAC-15 foi superior a $2.800 \mathrm{~kg} / \mathrm{ha}$, representando um acréscimo substancial, mesmo em relação ao padrão de maior produtividade, IAC-12. O IAC-15 foi o tratamento que apresentou o melhor rendimento, suplantando Bossier em tres dos cinco experimentos, com média de $2.955 \mathrm{~kg} / \mathrm{ha}$, cerca de $38 \%$ a mais que o padräo.

No que concerne à altura de planta - Quadro 5 - o cultivar Bossier e as linhagens IAC82-3185 e IAC82-3127 não alcançaram, em média, o limite de $0,60 \mathrm{~m}$. Já as linhagens IAC82-1291, IAC82-1238 e IAC82-1093 e o cultivar IAC-15, mesmo em locais em que houve prejuizo para o desenvolvimento das plantas, superaram essa marca.

QUADRO 4. Produtividade de linhagens e cultivares de soja avaliados nos ensaios regionais realizados pelo Instituto Agronômico, em cinco localidades, em 1984/85

\begin{tabular}{|c|c|c|c|c|c|c|c|}
\hline \multirow{2}{*}{$\begin{array}{c}\text { Cultivares } \\
e \\
\text { Linhagens }\end{array}$} & \multirow{2}{*}{ Campinas } & \multicolumn{2}{|c|}{ Guaira (1) } & \multirow{2}{*}{ Ituverava } & \multirow{2}{*}{ Orlândia } & \multirow{2}{*}{ Média } & \multirow{2}{*}{$\begin{array}{l}\text { Indice } \\
\text { relativo }\end{array}$} \\
\hline & & E.R. & F.R. & & & & \\
\hline & & & $-\mathrm{kg} / \mathrm{h}$ & & & - & \\
\hline Bossier & 1.592 & 2.014 & 3.137 & 2.575 & 1.387 & 2.140 & 100 \\
\hline IAC-12 & 1.989 & 2.275 & 3.000 & 2.490 & $2.375+$ & $2.427+$ & 114 \\
\hline IAC82-3185 & $2.370+$ & 2.072 & 3.205 & $2.917+$ & 1.675 & $2.449+$ & 115 \\
\hline IAC82-1291 & 1.972 & 2.442 & 3.515 & $2.104-$ & $2.324+$ & $2.472+$ & 116 \\
\hline IAC82-3127 & $2.370+$ & 1.834 & 2.387 & 2.422 & $1.045-$ & 2.012 & 94 \\
\hline IAC82-1093 & $2.582+$ & $2.779+$ & 3.665 & 2.714 & $2.425+$ & $2.834+$ & 133 \\
\hline IAC82-648 & 1.800 & 2.104 & 2.787 & 2.754 & $1.872+$ & 2.264 & 106 \\
\hline IAC82-1112 & $2.147+$ & 2.447 & 3.257 & 2.607 & $2.474+$ & $2.587+$ & 121 \\
\hline IAC82-3209 & $2.457+$ & $2.630+$ & 3.962 & 2.580 & $2.604+$ & $2.847+$ & 133 \\
\hline IAC82-1173 & $2.470+$ & 2.384 & 2.659 & 2.730 & $2.434 t$ & $2.535+$ & 119 \\
\hline IAC-15 & $2.720+$ & $2.605+$ & 3.607 & 2.767 & $3.075+$ & $2.955+$ & 138 \\
\hline IAC82-1238 & $2.704+$ & $2.704+$ & 3.415 & 2.690 & $2.679+$ & $2.852+$ & 134 \\
\hline Média & 2.270 & 2.357 & 3.217 & 2.612 & 2.197 & 2.530 & \\
\hline C.V.\% & 14,4 & 13,8 & 17,9 & 8,7 & 10,6 & & \\
\hline d.m.s. $(5 \%)$ & 472 & 470 & 827 & 329 & 335 & 230 & \\
\hline
\end{tabular}

(1) E.R.: Escritório Regional do AC. F.R.: Fazenda Rodeio.

+ e-: diferem do cultivar Bossier ao nivel de $5 \%$, para mais ou para menos respectivamente. 
QUADRO 5. Altura média de plantas de linhagens e cultivares de soja obtida nos ensaios regionais efetuados pelo Instituto Agronômico, en 1984/85

\begin{tabular}{|c|c|c|c|c|c|}
\hline $\begin{array}{l}\text { Cultivares } \\
\text { e Linhagens }\end{array}$ & Campinas & $\begin{array}{c}\text { Guaira } \\
\text { E.R. }\end{array}$ & Ituverava & Orlândia & Média \\
\hline & & & $-\mathrm{cm}$ & $\ldots$ & 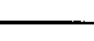 \\
\hline Bossier & 62 & 51 & 68 & 40 & 56 \\
\hline IAC-12 & 73 & 54 & 84 & 47 & 65 \\
\hline IAC82-3185 & 69 & 54 & 67 & 38 & 57 \\
\hline IAC82-1291 & 102 & 95 & 114 & 82 & 99 \\
\hline IAC82-3127 & 77 & 43 & 49 & 30 & 50 \\
\hline IAC82-1093 & 87 & 79 & 102 & 68 & 84 \\
\hline IAC82-648 & 78 & 62 & 81 & 57 & 70 \\
\hline IAC82-1112 & 81 & 79 & 91 & 58 & 78 \\
\hline IAC82-3209 & 77 & 74 & 85 & 50 & 72 \\
\hline IAC82-1173 & 82 & 83 & 98 & 57 & 80 \\
\hline IAC-15 & 90 & 84 & 97 & 70 & 86 \\
\hline IAC82-1238 & 87 & 100 & 109 & 83 & 95 \\
\hline Média & 80 & 71 & 87 & 57 & 74 \\
\hline
\end{tabular}

(1) E.R.: Escritório Regional do IAC.

Considerando as análises individuais dos ensaios regionais de 1985/86 - Quadro 6 - somente em Gualra não houve diferenças significativas entre tratamentos. O IAC-15 diferiu do Bossier na análise conjunta dos resultados, suplantando-0 em 14\%.

No quadro 7, verifica-se que, com exceção da linhagem IAC82-3185, em Guaíra, e do cultivar FT-10 em ltuverava, a altura de $0,60 \mathrm{~m}$ foi atingida pelos demais genótipos em todas as localidades e também por aqueles na média de todos os ensaios.

Observa-se, pelo quadro 8 - resultados dos testes regionais do Sistema de Avaliação de Cultivares implantados pelo IAC/CATI - que foram detectadas diferenças significativas entre tratamentos em Ituverava e Gualra, em 1985/86, e em Ipuã, Campinas e Presidente Venceslau, em 1986/87.

O cultivar IAC-15, na média dos dois anos, apresentou melhor desempenho, produzindo cerca de $18 \%$ a mais que o 'Bossier', bem acima do limite de $3 \%$ exigido pelo Sistema de Avaliação para recomendação. Diferiu estatisticamente do material referencial, em Ituverava, 85/86, e em Ipuã e Campinas, 86/87, assim como na análise conjunta do primeiro e do segundo ano. Verificou-se também significância na comparação entre as médias de IAC-15e Bossier, quando 
se realizou a análise conjunta de todos os ensaios ignorando anos, na qual se utilizou uma adaptação do método proposto inicialmente por Cochran em 1954 (GOMES, 1987), visto haver elevada discrepancia entre os quadrados medios residuais da análise da variancia dos diferentes locais.

Em relação à aluura de planta, o 'IAC-15' também se destacou, atingindo a marca de $85 \mathrm{~cm}, 14$ a mais que o padrăo 'Bossier' - Quadro 9.

A maior altura do 'IAC-15' refiete a presença de perfodo juvenil longo em seu arcabouço fisiológico. Este attibuto irá possibilitar a antecipaçăo de semeadura, quando há maiores rendimentos e produçăo de sementes de alta qualidade fisiológica, em cultivos sob irrigaçăo, tanto após a cultura de verăo em áreas sujeitas a geadas como no outono-inverno em áreas livres desse flagelo climático.

Com os resultados obtidos, chega-se à conclusão que o cultivar IAC-15 6 superior ao padrão, tanto em altura de planta como em produtividade, o que justifica seu lançamento para utilizaçăo na sojicultura paulista.

QUADRO 6. Produtividade de linhagens e cultivares de soja obtida nos ensaios regionais implantados pelo Instituto Agronómico, em 1985/86

\begin{tabular}{|c|c|c|c|c|c|c|}
\hline \multirow{3}{*}{$\begin{array}{l}\text { Cultivares } \\
\text { e Linhagens }\end{array}$} & \multicolumn{4}{|c|}{ Localidades } & \multirow{3}{*}{ Média } & \multirow{3}{*}{$\begin{array}{l}\text { Índice } \\
\text { relativo }\end{array}$} \\
\hline & \multirow[t]{2}{*}{ Campinas } & \multicolumn{2}{|c|}{ Ituverava } & \multirow[t]{2}{*}{ Guaíra } & & \\
\hline & & K.O. (1) & M.Y. (2) & & & \\
\hline & & & $-\mathrm{kg} / \mathrm{ha}-$ & & $\longrightarrow$ & \\
\hline Bossier & 1.790 & 2.737 & 2.120 & 2.289 & 2.234 & 100 \\
\hline $\mid A C-12$ & $2.205+$ & 3.107 & 2.245 & 2.290 & 2.462 & 111 \\
\hline $\mid A C-15$ & $2.155+$ & 3.024 & $2.587+$ & 2.340 & $2.527+$ & 114 \\
\hline IAC82-1238 & $2.245+$ & $3.212+$ & 2.182 & 2.280 & 2.480 & 111 \\
\hline IAC82-3209 & 1.800 & $3.175+$ & 2.130 & 2.014 & 2.280 & 102 \\
\hline IAC82-1093 & 1.940 & 2.882 & 2.292 & 2.707 & 2.455 & 110 \\
\hline FT-10 & $2.130+$ & $3.315+$ & 2.345 & 2.497 & $2.572+$ & 116 \\
\hline IAC79-440 & 2.030 & $3.345+$ & $2.722+$ & 2.430 & $2.632+$ & 118 \\
\hline IAC80-1146 & $2.462+$ & $3.307+$ & 2.375 & 2.097 & $2.560+$ & 115 \\
\hline IAC80-1441 & $2.454+$ & $3.424+$ & $2.539+$ & 2.484 & $2.725+$ & 122 \\
\hline IAC82-3185 & $2.082+$ & 3.099 & 2.267 & 2.290 & 2.435 & 109 \\
\hline IAC79-986 & $2.095+$ & 2.712 & $2.545+$ & 2.184 & 2.384 & 107 \\
\hline Média & 2.115 & 3.112 & 2.362 & 2.325 & 2.479 & \\
\hline $\mathrm{CV} \%$ & 8,3 & 9,3 & 9,4 & 14,8 & & \\
\hline Isd(0,05\%) & 252 & 249 & 320 & 497 & 259 & \\
\hline
\end{tabular}

(1) Kiniti Okano. (2) Mitsuo Yarnaguti.

+ : diferem do cultivar Bossier ao nivel de $5 \%$. 


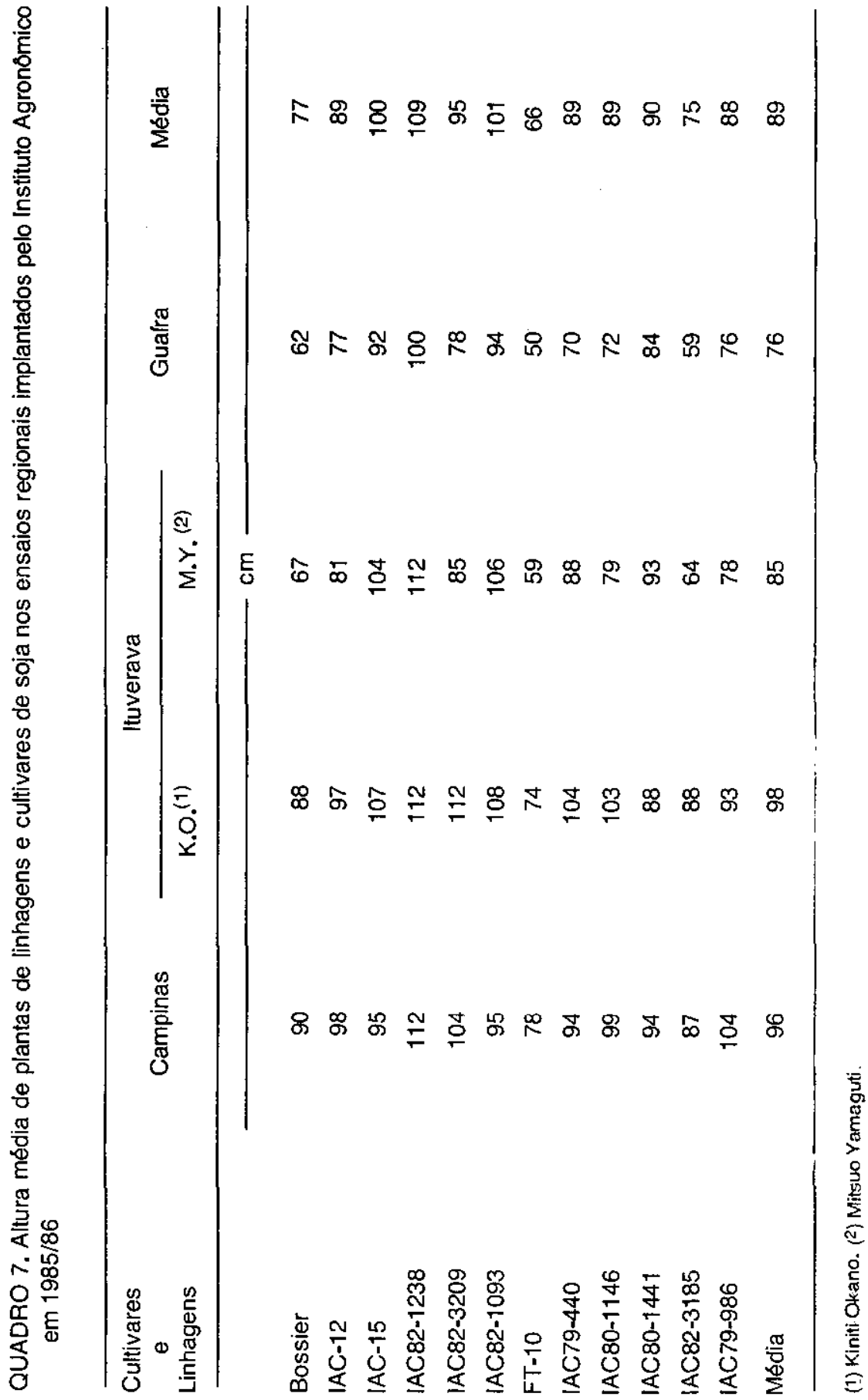




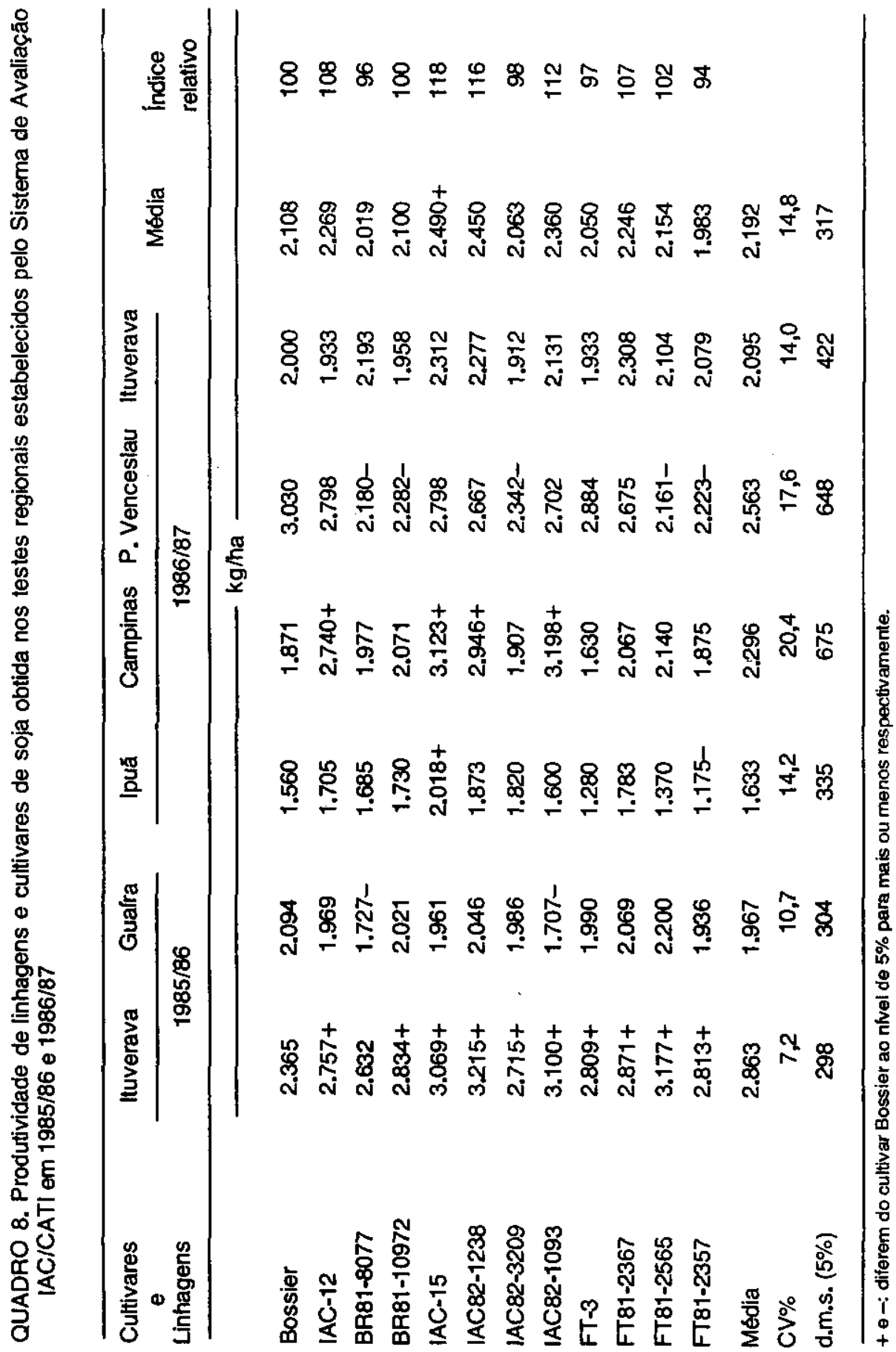




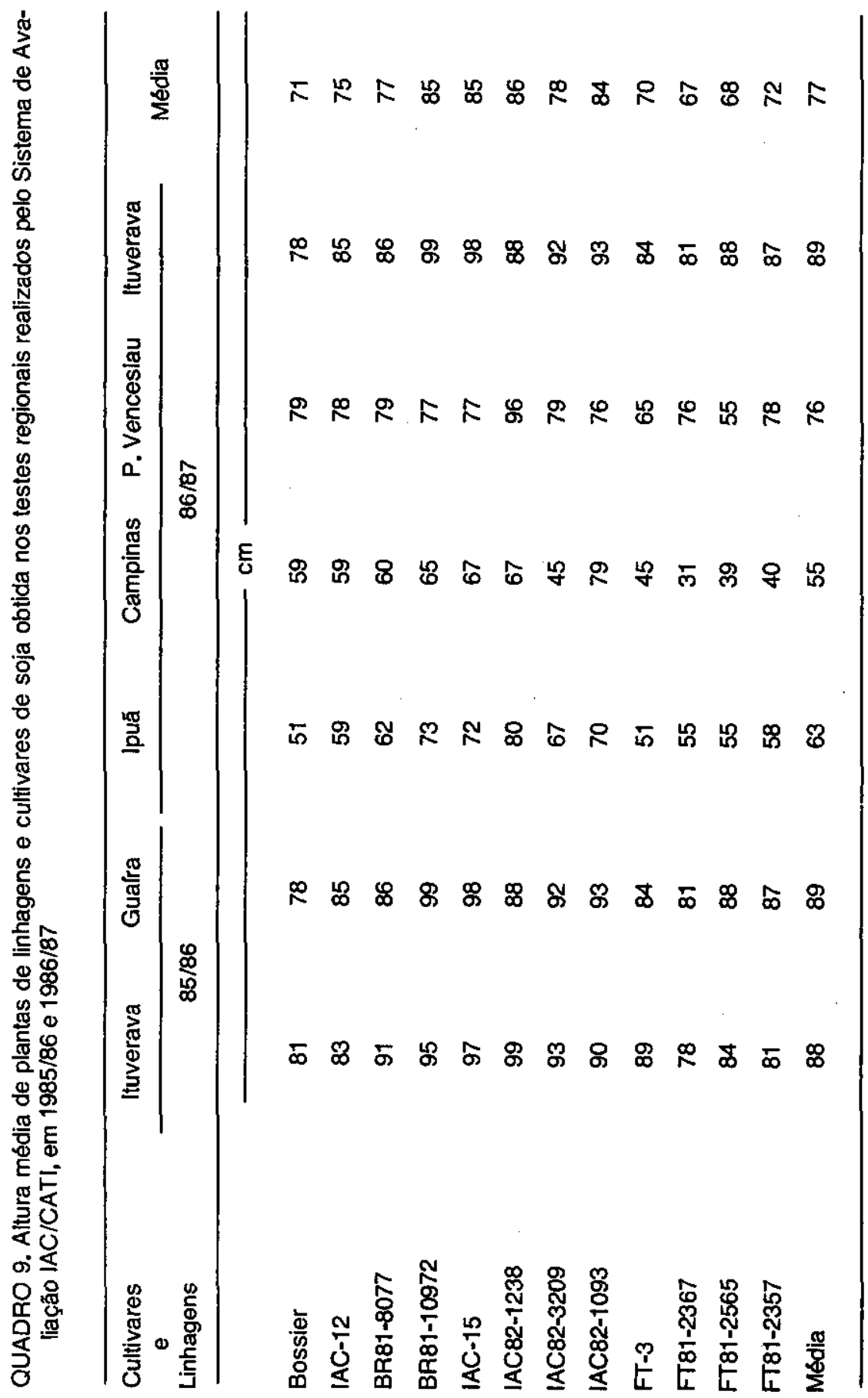




\section{AGRADECIMENTOS}

Os autores agradecem a colaboraçăo aos engenheiros-agronomos participantes do Sistema de Avaliaçāo e Recomendaçăo de Cultivares de Soja para o Estado de São Paulo, em especial nas pessoas de: Carlos Mendes Junior, Oscar Alexander Campagno Eichel, Oswaldo Minoru Doi, Paulo Cesar da Luz Leảo e Yandir Pereira da Silva, $\theta$ dos auxiliares agropecuários Aparecido da Silva $\theta$ Valdeir Biudes Hermoso.

\section{REFERENCIAS BIBLIOGRAFICAS}

ALMEIDA, L.D'A. de; KIIHL, R.A. de S.; SPEHAR, C.R.; VILLELA, L.; MONTEIRO, P.M.F.O.; ROLIM, R.B.; ARANTES, N.E.; MIRANDA, M.A.C. do \& SOUZA, P.I.M. 'Doko': uma cultivar para o Brasil Central. In: SEMINARIO NACIONAL DE PESQUISA DE SOJA, 2., Braslia, 1981. Anais. Londrina, EMBRAPA CNPSo, 1982. v.2, p.412-415. (EMBRAPA-CNPSo. Documentos, 1)

CAMARGO, M.B.P. de; MIRANDA, M.A.C. de; PEDRO JÚNIOR, M.J.; PEREIRA, J.C.V.N.A. \& MASCARENHAS, H.A.A. Estimativa da produtividade potencial de cultivares de soja nas condiçöes climáticas de Ribeiräo Preto, SP. Bragontis, Campinas, 47(2):277-288, 1988.

GOMES, F.P. Curso de estatstice experimental. 12. ed. Piracicaba, Nobel, 1987. 467p.

HARTWG E.E. \& KIIHL, R.A.de S. Identification and utilization of a delayed flowering character in soybeans for shortday conditions. Field Crops Research, Amsterdam, 2:145-151, 1979.

KIIHL, R.A. de S. Influence of photoperiod upon certain grouth and reproductive characteristics of soybean varieties and segregation of characters in the $F_{2}$ generation. Mississippi, Mississippi Stat University, 1968. 56p. Dissertaçăo (Mestrado).

- Inheritance studies of two cheracteristics in soybeans (Glycine max (L.): I. Resistance to soybean mosaic virus; II. Lat flowering under short-day conditions. Mississippi, Mississippi Stato University, 1976. 56p. Dissertaçăo (Doutorado).

; ALMEIDA, L.D'A. de; CAMPELO, G.J.A.; BAYS, I.A.; GOMES, E.R.; MONTEIRO, P.M.F.O. \& MIRANDA, M.A.C. do. Tropical': uma cultivar brasileira para baixas latitudes. In: SEMINARIO NACIONAL DE PESQUISA DE SOJA, 2., Brasilia, 1981. Anais. Londrina, EMBRAPA-CNPSo, 1982. v.2, p.463-465. (EMBRAPA-CNPSo. Documentos, 1)

LIMA NETO, V. da C. \& COSTA, A.S. Localizaçăo de resistencia ao virus do mosaico comum em soja. Summa Phytopsthologica, Piracicaba, 1(3):221230, 1975.

MASCARENHAS, H.A.A.; MURANDA, M.A.C. de; TISSELLIFILHO, 0.; BULISANI, E.A.; ALMEIDA, L.D'A. de \& BRAGA, N.R. Contribuiçăo do Instituto Agronómico na evoluçáo de cultura da soja em Săo Paulo. 2.ed. rev. atual. Campinas, Instituto Agronomico, 1983. 50p. (Circular, 32) 
MIRANDA, M.A.C. de; MASCARENHAS, H.A.A.; BRAGA, N.R. \& KIIHL, R.A. do S. Cultivar de soja IAC-8. Campinas, Instituto Aoronomico, 1980. 8p. (Circular, 1131

NOGUEIRA, S. dos S.S. Cido biológico, caracteristicas fisiologicas, produçäo e composição quimica da semente dos cultivares de soja (Glycine max (L.) Merrill) UFV-1 e IAC-7 em diversas épocas de semeadura. Piracicaba, ESALO, 1983. 96p. Tese (Doutorado).

PEDRO JÚNIOR, M.J.; CAMARGO, M.B.P. de; MIRANDA, M.A.C. de; BRUNINI, O.; ORTOLANI, A.A. \& ALFONSI, R.R. Test de modelo agrometoorologico para estimativa da produtividade da cultura da soja de ciclo precoce. In: CONGRESSO BRASILEIRO DE AGROMETEOROLOGIA, 3., Campinas, 1983. Anais. Campinas, Sociedade Brasileira de Agrometeorologia, 1984. p.11-17.

PROGNOSTICO AGRICOLA. São Paulo, Instituto de Economia Agricola, $1988 / 89$.

REZENDE, J.A.M.; MIRANDA, M.A.C. de \& MASCARENHAS, H.A.A. Comportamento de cultivares de soja em relaçāo a área foliar comida por lagarta das folhas. Bragantia, Campinas, 30:161-166, 1980.

SEDIYAMA, T.; ALMEIDA, L.D'A. de; MIYASAKA, S. \& KIIHL, R .A. de S. Genética e melhoramento. In: FUNDACAO CARGILL, Campinas. A soja no Brasil Central. 2.ed. rev. ampl. Campinas, 1982. p.23-74.

SPECHT, J.E. \& WLLLAM, J.H. Contribution of genetic tochnology to soybean productivity - retrospect and prospect. In: FEHR, W.R., ed. Genetic contributions to yield of five major crops plants. Madison, American Society of Agronomy, 1984. p.4974.

STEEL, R.G.D. \& TORRIE, J.H. Analysis of variance l: the one-way classification; the least significant difference. In:-—— \& Principles and procedures of statistics. New York, McGrawHill, 1960. cap.7, p.106-107.

TAVARES, D.Q.; MIRANDA, M.A.C. de; UMINO, C.Y. \& DIAS, G.M. Caracteristicas estruturais do tegumento de sementes permeáveis e impermeáveis de linhagens de soja, Glycine mox (L.) Merrill. Revisto Brasileira de Botanica, Sảo Paulo, 10(2):147-153, 1987.

; UMINO, C.Y.; DIAS, G.M. \& MIRANDA, M.A.C. de. Compostos fenolicos no tegumento de sementes de linhagens de soja permeável $\theta$ impermeável. Revisto Brasileira de Botanica, São Paulo, 9(2):167-171, 1986.

TISSELLI FILHO, 0 . Inheritance study of the long-jivenile characteristics in soybeans under long-and short-day conditions. Mississippi, Mississippi Stato University, 1981. 77p. Dissertação (Doutorado).

TOLEDO, J.F.F. de. Predicting the inbreeding and the outcrossing potential of soybean (G/ycine max (L.) Merrill) varieties. Revisto Brasileiro de Genética, Ribeirăo Preto, 10(3):543-558, 1987. 